Original Research Paper

\title{
Pelatihan Budidaya Sayuran Hidroponik Menggunakan Sistem Wick Sebagai Usaha Pemberdayaan Masyarakat Di Desa Cenggu
}

\author{
Nur Hayati ${ }^{1 *}$, I Gde Mertha ${ }^{2}$

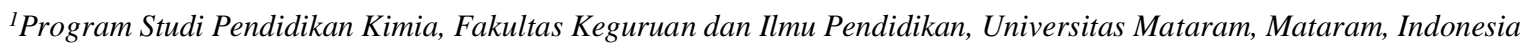 \\ ${ }^{2}$ Program Studi Pendidikan Biologi, Fakultas Keguruan dan Ilmu Pendidikan, Universitas Mataram, Mataram, Indonesia
}

DOI: https://doi.org/10.29303/jpmpi.v3i2.588

Sitasi:. Hayati, N., \& Mertha, I. G. (2020). Pelatihan Budidaya Sayuran Hidroponik Menggunakan Sistem Wick Sebagai Usaha Pemberdayaan Masyarakat Di Desa Cenggu. Jurnal Pengabdian Magister Pendidikan IPA, 3(2)

\author{
Article history \\ Received: 25 Oktober \\ Revised: 15 Nopember \\ Accepted: 29 Desember \\ *Corresponding Author: Nur \\ Hayati, Program Studi \\ Pendidikan Kimia, Fakultas \\ Keguruan dan Ilmu Pendidikan, \\ Universitas Mataram, Mataram, \\ Indonesia \\ Email: hnur63820@gmail.com
}

\begin{abstract}
Berdasarkan analisis situasi diketahui bahwa sebagian besar masyarakat Desa Cenggu bermata pencarian disektor pertanian dan produk yang dihasilkan berupa kacang kedelai, padi, dan bawang merah tetapi untuk jenis tanaman sayuran produksinya sangat rendah dan bahkan tidak dibudidayakan oleh penduduk setempat. Padahal, potensi pengembangan pertanian pada skala rumah tangga atau perkarangan cukup besar. Tujuan program ini adalah (1) Untuk memberdayakan masyarakat Desa Cenggu dengan memberikan pelatihan budidaya tanaman sayuran dengan hidroponik sistem wick, dan (2) meningkatkan pengetahuan masyarakat tentang teknik hidroponik. Konsep hidroponik merupakan budidaya menanam dengan memanfaatkan air/larutan bernutrisi tanpa menggunakan tanah dengan menekankan pada pemenuhan kebutuhan nutrisi. Metode yang digunakan dalam program ini adalah sosialisasi program, pelatihan dan praktik pembuatan hidroponik dan pendampingan serta evaluasi kegiatan. Berdasarkan hasil program yang dijalankan dapat disimpulkan bahwa budidaya tanaman sayuran hidroponik sistem wick telah berhasil memberdayakan ibu-ibu rumah tangga masyarakat Desa Cenggu dalam meningkatkan minat untuk memanfaatkan perkarangan sebagai lahan penanaman sayuran. Masyarakat memberikan respon yang sangat positif terhadap kegiatan yang dilakukan dan menilai kegiatan ini sangat bermanfaat.
\end{abstract}

Keywords: Hidroponik; Sistem wick; Sosialisasi; Pelatihan; Pemberdayaan

\section{Pendahuluan}

Cenggu merupakan salah satu desa di Kecamatan Belo, Kabupaten Bima, Provinsi NTB dengan luas wilayah $720.70 \mathrm{Ha}$ dengan jumlah penduduk 3.220 jiwa. Sebagian besar masyarakat Desa Cenggu bermata pencarian disektor pertanian dan produk yang dihasilkan berupa kacang kedelai, padi dan bawang merah di ladang sedangkan untuk jenis tanaman sayuran produksinya sangat rendah bahkan tidak dibudidayakan oleh masyarakat Cenggu. Hal ini disebabkan kurangnya minat serta pengetahuan masyarakat tentang budidaya tanaman jenis sayuran. Padahal untuk menanam jenis sayuran bisa dilakukan di pekarangan rumah masing-masing. Sehingga pengolahan lahan pekarangn rumah menjadi produktif.

Kebutuhan akan hasil pertanian terus meningkat seiring jumlah penduduk yang semakin bertambah. Salah satu kebutuhan hasil pertanian yang dibutuhkan penduduk adalah hasil tanaman sayuran sebagai bahan pangan. Sementara hasil pertanian jenis tanaman sayuran sangat rendah di Desa Cenggu. Kondisi yang demikian membutuhkan solusi untuk mengatasinya. Salah satunya dengan memanfaatkan lahan perkarangan rumah untuk dijadikan sebagai lahan budidaya sayuran. Apabila dimanfaatkan secara optimal 
maka permasalahan tersebut kemungkinan besar dapat dikurangi.

Salah satu teknik bercocok tanaman sayuran yang dapat diterapkan oleh masyarakat adalah teknik hidroponik sistem wick. Hidroponik adalah suatu metode bercocok tanam tanpa menggunakan media tanah, melainkan dengan menggunakan larutan mineral bernutrisi atau bahan lainnya yang mengandung unsur hara seperti sabut kelapa, serat mineral, pasir, pecahan batu bata, serbuk kayu, dan lain-lain sebagai pengganti media tanah. Teknologi budidaya pertanian dengan sistem hidroponik diharapkan menjadi salah satu alternatif bagi masyarakat yang mempunyai lahan terbatas atau pekarangan, sehingga dapat dijadikan sebagai sesuatu yang berguna (Surahman, 2018). Usaha hidroponik bisa dilakukan secara kecil-kecilan di rumah sebagai suatu hobi ataupun secara besarbesaran dengan tujuan komersial. Budididaya tanaman ini tidak memerlukan lahan yang luas, bisa juga dilakukan di pekarangan rumah. Perawatan hidroponik sangat mudah, karena tumbuhan, tanaman atau sayur-sayuran dapat tumbuh dengan mudah tanpa menggunakan tanah, hanya dengan talang air, botol-botol kemasan yang sudah tidak terpakai dan juga bisa memanfaatkan barangbarang yang sudah tidak diperlukan seperti ember, baskom dan sebagainya (Satya et al., 2017).

Beberapa jenis hidroponik yakni Wick, Deep Water Culture (DWC), EBB dan Flow (Flood \& Drain), Drip (recovery atau non-recovery), Nutrient Film Technique (NFT), dan Aeroponik (Puspasari et al., 2018). Dalam kegiatan ini digunakan jenis hidroponik sistem wick. Sistem wick merupakan salah satu metode dari hidroponik yang menggunakan sumbu atau penyambung antara nutrisi dengan media tanam. Sistem ini yang paling simpel dan sederhana. Sumbu yang digunakan adalah sumbu yang memiliki daya kapilaritas tinggi serta cepat lapuk. Cara ini sama dengan mekanisme kompor minyak, yaitu sumbu berfungsi untuk menyerap air. Sumbu terbaik adalah kain flanel sangat cocok digunakan untuk sistem wick. Kelebihan sistem hidroponik wick adalah tanaman mendapat suplai air dan nutrisi secara terusmenerus, biaya alat yang murah, mempermudah perawatan karena kita tidak perlu melakukan penyiraman, tidak tergantung aliran listrik (Narulita et al., 2019). Prinsip hidroponik sistem sumbu sangat mudah diaplikasikan, karena memiliki tingkat kesulitan yang sangat rendah. Selain itu semua bahan untuk membuat instalasi hidroponik bisa diperoleh dengan barang-barang bekas (Kamalia et al., 2017). Alat yang digunakan dalam kegiatan ini menggunakan barang bekas disekitar rumah atau limbah rumah tangga, seperti botol air mineral, kain flanel, gelas plastik dan lainnya sementara barang-barang tersebut memiliki manfaat untuk dijadikan media tanam hidroponik sehingga terdapat ide untuk memberikan pelatihan/pemberdayaan kepada masyarakat Desa Cenggu.

Pemberdayaan adalah keadaan yang terjadi atau hal-hal yang dilakukan dilingkungan masyarakat dengan upaya membangun pembangunan yang bertumpu pada masyarakat itu sendiri. Tujuan dilakukan pemberdayaan adalah membuat masyarakat menjadi berdaya. Berdaya yang dimaksud disini adalah upaya-upaya atau unsur-unsur yang meningkatkan masyarakat untuk bertahan dan mengembangkan diri untuk mencapai kemajuan. Maju yang dimaksud adalah untuk memajukan perekonomian seiring dengan majunnya tingkat SDM (Solikhah et al., 2018). Adapun pemberdayaan yang akan dilakukan adalah dengan memberikan sosialisasi dan pelatihan mengenai hidroponik. Pemilihan pemberdayaan masyarakat Cenggu dengan memberikan pelatihan hidroponik dengan alasan: (1) masyarakat Cenggu memiliki lahan yang cukup untuk diterapkan tanaman hidroponik dan sebagian besar masyarakat Cenggu khususnya ibu rumah tangga tidak memiliki pekerjaan sampingan sehingga bercocok tanam dapat meningkatkan perekonomian keluarga, (2) bercocok tanam dengan hidroponik tidak membutuhkan lahan yang luas untuk menerapkan tanaman hidroponik, (3) teknologi hidoroponik menggunakan sistem yang sederhana yakni sistem sumbu (wick system), (4) dapat menstabilkan hasil perekonomian masyarakat Cenggu khususnya bahan pangan sayuran serta dapat menghemat pengeluaran, dan (5) barang-barang bekas yang tidak bernilai dapat dimanfaatkan sebagai media tanam hidroponik.

Berdasarkan latar belakang tersebut maka diperlukan suatu upaya untuk memperkenalkan usulan program tim kami berupa pelatihan budidaya tanaman sayuran hidroponik dengan sistem wick sebagai usaha memberdayakan masyarakat di Desa Cenggu. 


\section{Metode}

Metode yang digunakan dalam upaya mencapai target luaran yang telah direncanakan adalah ceamah, diskusi, tanya jawab, unjuk kerja (praktik), dan pendampingan dengan tahapan sebagai berikut:

\section{Sosialisasi program}

Sosialisasi program hidroponik ini melibatkan masyarakat khusunya ibu-ibu rumah tangga. Sosialisasi dilaksanakan dengan ceramah interaktif secara langsung, dan dilakukan diskusi dan tanya jawab.

\section{Praktik pembuatan hidroponik}

Setelah seluruh warga masyarakat khususnya ibu-ibu rumah tangga memahami materi tentang hidroponik, selanjutnya adalah pelatihan membuat hidroponik sistem wick mulai dari proses pembuatan tempat tanam, pembibitan sampai dengan proses pembuatan pupuk organik cair untuk tanaman hidroponik. Adapun alat dan bahan yang dapat digunakan untuk membuat hidroponik system ini adalah: (a) botol bekas, (b) kain flanel, (c) gelas plastik tempat tanam, (d) rockwol, (e) nutrisi/pupuk organik cair, (f) benih sayuran, dan (g) cat warna.

Menurut Solikhah et al. (2018) bahwa teknik penanaman hidroponik sistem wick sangat sederhana, mulai dari penyemaian bibit, penanaman bibit pada media hidroponik yang telah diberi sumbu, penambahan nutrisi secara berkala, dan persiapan panen.

\section{Pendampingan}

Untuk memantau bahwa program dijalankan, maka tahapan selanjutnya dilakukan kegiatan pendampingan. Proses pendampingan ini dilaksanakan secara fisik dengan datang langsung disekitaran rumah warga. Cara tersebut dirasa lebih efektif dan efisien dikarenakan masyarakat dapat terlibat dan melihat langsung proses pembuatan alatnya, serta pembibitan dan pembuatan pupuk organik cair.

\section{Evaluasi kegiatan}

Evaluasi untuk mengetahui keberhasilan dari kegiatan ini dilakukan dengan cara sebagai berikut:

a. Kegiatan sosiaialisasi dan penyampaian materi dievaluasi berdasarkan partisipasi dan keaktifan mitra. Kegiatan dianggap berhasil apabila $60 \%$ dari mitra peserta menunjukkan partisipasi dan keaktifannya.

b. Secara keseluruhan program dianggap berhasil apabila minimal $55 \%$ ibu-ibu peserta pelatihan memiliki hidroponik di rumah masing-masing, khususnya tanaman sayur-sayuran, selain itu juga dilihat dari tingkat keberhasilan tanaman hidroponik sampai hasil panen.

\section{Hasil dan Pembahasan}

Kegiatan pengabdian kepada masyarakat ini terbagi menjadi 3 program besar yaitu kegiatan sosialisasi dan pelatihan guna penyampaian materi terkait hidroponik sistem wick dan program praktik pembuatan hidroponik sistem wick.

\section{Kegiatan sosialisasi budidaya sayuran hidroponik} sistem wick

Teknik hidroponik sistem wick merupakan salah satu sistem hidroponik yang paling sederhana dan digunakan oleh kalangan pemula. Sistem ini menggunakan tangki yang berisi larutan nutrisi yang mengalir kedalam media pertumbuhan dari dalam wadah melalui sejenis sumbu yang biasanya adalah kain flanel. Prinsip yang diterapkan pada sistem ini adalah kapilaritas (Puspasari et.al., 2018).

Sosialisasi program dihadiri aparat desa dan mitra target sasaran, yaitu ibu-ibu rumah tangga. Adapun beberapa hal yang disampaikan pada saat sosialisasi, yaitu: (a) peranan ibu rumah tangga dalam pemberdayaan masyarakat, (b) konsep dasar hidroponik sistem wick, dan (c) keunggulan hidroponik sistem wick. Pada sesi diskusi dan tanya jawab, kepala desa dan masyarakat memberikan apresiasi yang tinggi terhadap program yang diusung dan berharap keberlanjutan program bisa tetap terjamin.

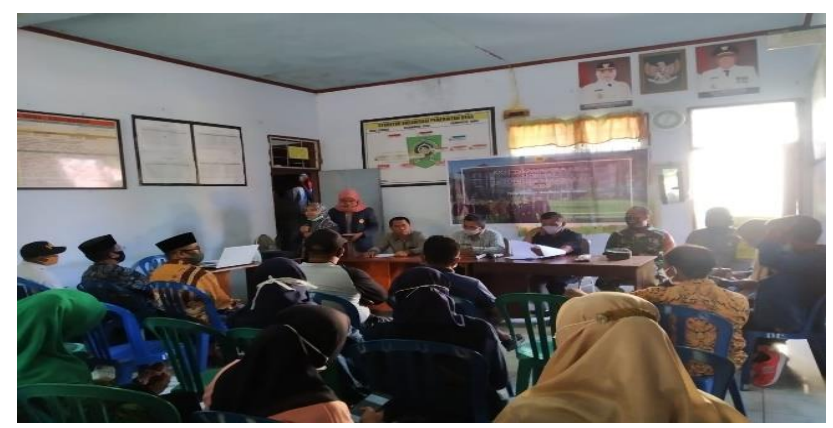

Gambar 1. Sosialisasi budidaya sayuran hidroponik sistem wick. 
Kegiatan pelatihan budidaya sayuran hidroponik sistem wick

Tanaman yang digunakan dalam pelatihan praktik budidaya sayuran hidroponik sistem wick bagi ibu-ibu pada RT 10/RW 04 adalah kangkung dan sawi. Adapun kegiatan pelatihan dilakukan satu kali sebagai berikut:

\section{a. Pelatihan semai bibit}

Tahap pertama dari pelatihan ini adalah penyiapan alat dan bahan yang digunakan untuk penyemaian bibit. Alat dan bahan yang digunakan adalah rockwool, bibit, air, nampan/tray semai, dan tusuk gigi.

Tahap selanjutnya adalah proses penyemaian bibit. Media tanam yang digunakan menggunakan rockwool. Rockwool dipotong dengan ukuran menyesuaikan lebar gelas plastik air mineral bekas, kemudian dibuat lubang tanam menggunakan tusuk gigi, 4 lubang untuk bibit kangkung dan 1 lubang untuk bibit sawi. Selanjutnya rockwool diberi air hingga basah. Benih diletakkan dalam lubang tanam.

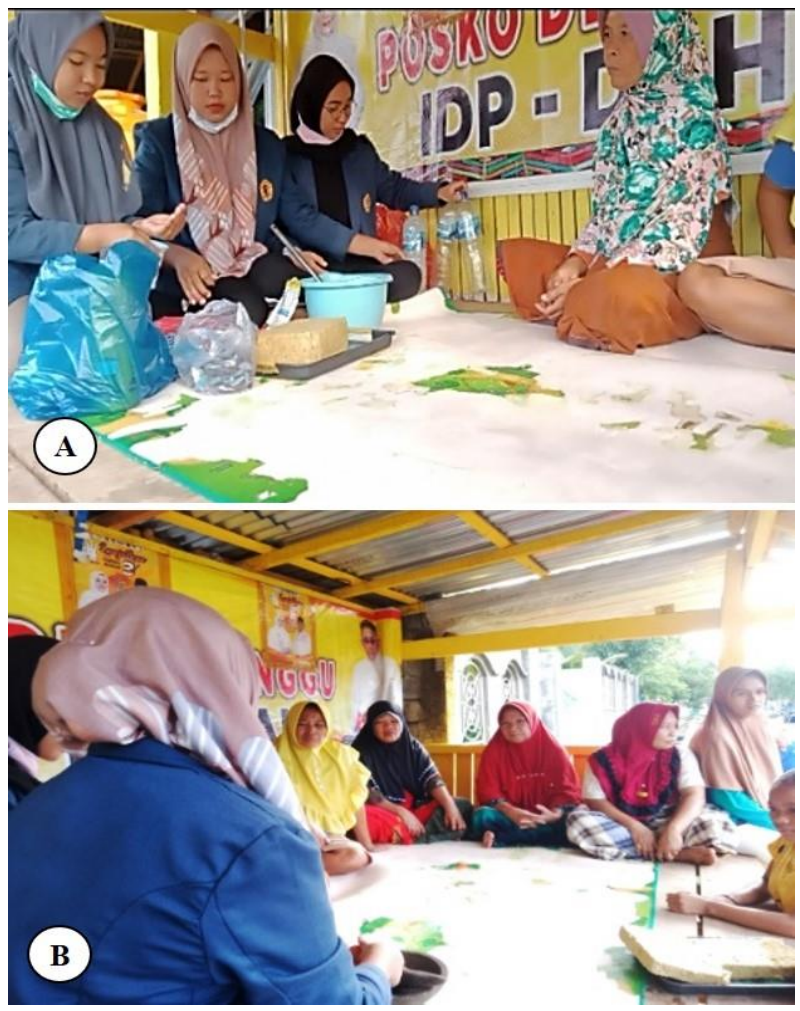

Gambar 2. Pelatihan penyemaian bibit sayuran. A. Penyiapan alat dan bahan. B. Penjelasan proses penyemaian.

\section{b. Pelatihan pembuatan larutan nutrisi}

Tahap pertama pelatihan ini adalah penyiapan alat dan bahan yang digunakan untuk pembuatan pupuk organik cair. Alat yang digunakan adalah botol bekas, baskom, pisau, ulekan/blender, pengaduk, dan corong. Sedangkan bahan baku yang dibutuhkan adalah pisang kepok, cangkang telur, air cucian beras, EM4, dan gula pasir.

Tahap selanjutnya adalah proses pembuatan pupuk organik cair sebagai berikut: (1) Pisang dipotong dengan ukuran 3-4 cm, lalu dimasukkan kedalam botol; (2) Cangkang telur dihancurkan sampai halus; (3) Dimasukkan 8 sendok gula kedalam air cucian beras kemudian diaduk sampai gula tersebut larut; (4) Dicampurkan cangkang telur yang sudah halus kedalam campuran gula dan air cucian beras, diaduk hingga tercampur rata kemudian ditungkan kedalam botol yang sudah berisi pisang kepok; (5) Dimasukkan $3 \mathrm{ml}$ cairan EM4 kedalam botol yang sudah terisi pisang kepok, gula, cangkang telur, dan air cucian beras, lalu dikocok hingga merata; (6) Campuran pupuk organik tersebut disimpan selama 7 hari ditempat yang gelap.

Setelah didiamkan selama 7 hari, langkah terakhir adalah pengemasan pupuk organik cair (POC) ke dalam botol plastik. Campuran POC yang sudah matang/siap pakai akan beraroma alami fermentasi/tape. Larutan tersebut kemudian disaring menggunakan penyaring untuk mendapatkan larutan yang bebas dari padatan bahan baku. Larutan POC yang sudah dikemas dalam botol siap diaplikasikan sebagai alternatif pengganti $A B$ Mix pada sistem penanaman hidroponik.

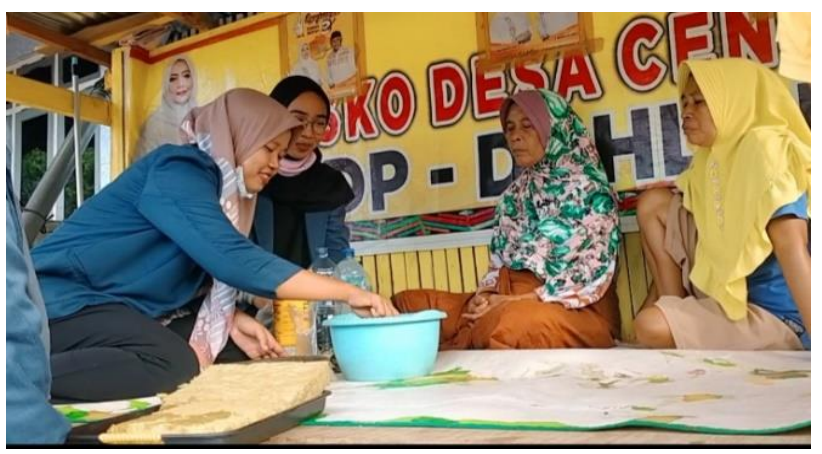

Gambar 3. Suasana pelatihan pembuatan pupuk organik cair.

\section{c. Pelatihan penanaman dan pemeliharaan}

Cara yang dapat diterapkan dalam penanaman hidroponik sangat sederhana, dengan langkah 
sebagai berikut: (1) Semaikan bibit pada media rockwol; (2) Masukkan bibit sayuran yang sudah tumbuh (berumur sekitar satu minggu) ke dalam lubang tanam yang telah diberi kain flanel sebagai sumbu untuk mengalirkan air dan nutrisi; (4) Masukkan nutrisi sesuai takaran kedalam bak/botol penampung; (5) Air dan nutrisi selalu ditambahkan setiap minggu; (6) Menunggu waktu panen (Ruswaji dan Chodariyanti, 2019).

Tahap pertama pelatihan penanaman adalah persiapan alat dan bahan. Alat yang digunakan adalah gelas plastik air mineral bekas, botol air mineral bekas, gunting, cutter, kain flanel, TDS meter, ember, penggaris, pensil, dan kompor. Bahan yang digunakan adalah benih, pupuk organik cair, cat, dan air.

Tahap kedua adalah proses pembuatan tempat tanam. Botol bekas air mineral di lubangi pada bagian samping sesuai ukuran gelas plastik air mineral dan dicat sesuai dengan warna yang diinginkan, jarak antar lubang disesuaikan. Gelas plastik air mineral di lubangi pada bagian bawah dan samping, dan ditambahkan kain flanel dibagian bawahnya. Air nutrisi dimasukkan kedalam botol plastik yang telah dilubangi.

Tahap selanjutnya adalah pemindahan hasil semai kedalam gelas plastik. Pemindahan semai dilakukan dengan cara memotong rockwool yang berisi bibit yang sudah berusia 7 hari, selanjutnya masing-masing kubus rockwool diletakkan dalam gelas air mineral. Gelas air mineral yang sudah berisi bibit siap tanam dimasukkan pada lubang yang tersedia di botol plastik bekas.

Pelatihan pemeliharaan dimulai dari pemberian nutrisi dan pengendalian hama sebagai berikut:

\section{(a) Pemberian nutrisi}

Nutrisi diberikan setiap 1 minggu sekali. Larutan nutrisi dicek EC dan pHnya. Jika nilai EC turun maka tambahkan nutrisi dalam larutan, sebaliknya jika nilai EC tinggi, tambahkan air kedalam larutan. Derajat keasaman air $(\mathrm{pH})$ yang digunakan adalah 6,5-7. Nilai $\mathrm{pH}$ diukur dengan menggunakan $\mathrm{pH}$ meter. Jika nilai $\mathrm{pH}$ turun tambahkan $\mathrm{KOH}$ pada larutan, dan jika nilai $\mathrm{pH}$ naik tambahkan $\mathrm{HCl}$ hingga $\mathrm{pH}$ menjadi 6,5-7. Jika air dibagian bawah botol habis, segera ditambahkan dengan mengukur $\mathrm{pH}$ dan nutrisinya agar tanaman tidak menjadi kering (Eddy et al., 2019).

\section{(b) Pengendalian hama dan penyakit}

Pengendalian hama dan penyakit dilakukan secara manual, dengan cara mengambil hama yang menyerang tanaman. Apabila tanaman kangkung dan sawi terserang penyakit, sebaiknya segera dibuang, untuk mencegah terjadinya penularan ke tanaman lain (Eddy et al., 2019).

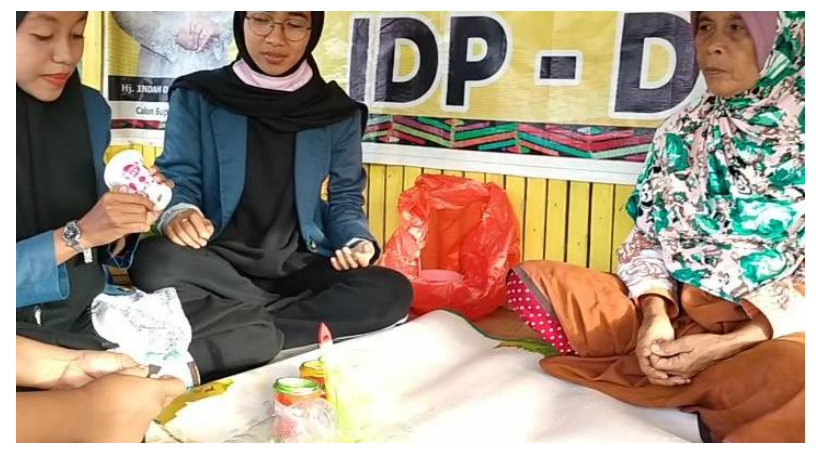

Gambar 4. Pelatihan praktik teknik penanaman hidroponik.

\section{Praktik pembuatan hidroponik sistem wick}

Setelah dilakukan sosialisasi dan pelatihan dilakukan praktik langsung pembuatan hidroponik sistem wick. Persiapan benih sampai menjadi bibit telah dilakukan. Setelah bibit berusia 1 minggu bibit siap ditanam di media hidroponik, dengan tetap harus dikontrol dan dievaluasi pertumbuhannya serta melakukan perawatan dengan mengganti larutan nutrisi tanaman.

Selanjutnya sampai waktu panen tiba harus tetap melakukan monitoring terhadap pertumbuhan tanaman, kita wajib mengontrol air dan memberi nutrisi pada tanaman yang dilakukan setiap 7 hari sekali sehingga secara otomatis bisa mengamati langsung bagaimana proses pertumbuhan tanaman. Pada masa ini juga bisa dikontrol hama atau penyakit yang menyerang, namun pada umunya penanaman hidroponik mampu meminimalisir serangan hama dan penyakit sehingga penggunaan pestisida kimia dapat dihindari dan dengan demikian otomatis tanaman dari hasil hidroponik tentunya akan lebih sehat (Ariati dan Raka, 2019).

Panen dilakukan ketika tanaman berusia 30 hari setelah melihat kondisi sayuran yang sudah siap panen dan tumbuh dengan subur. 


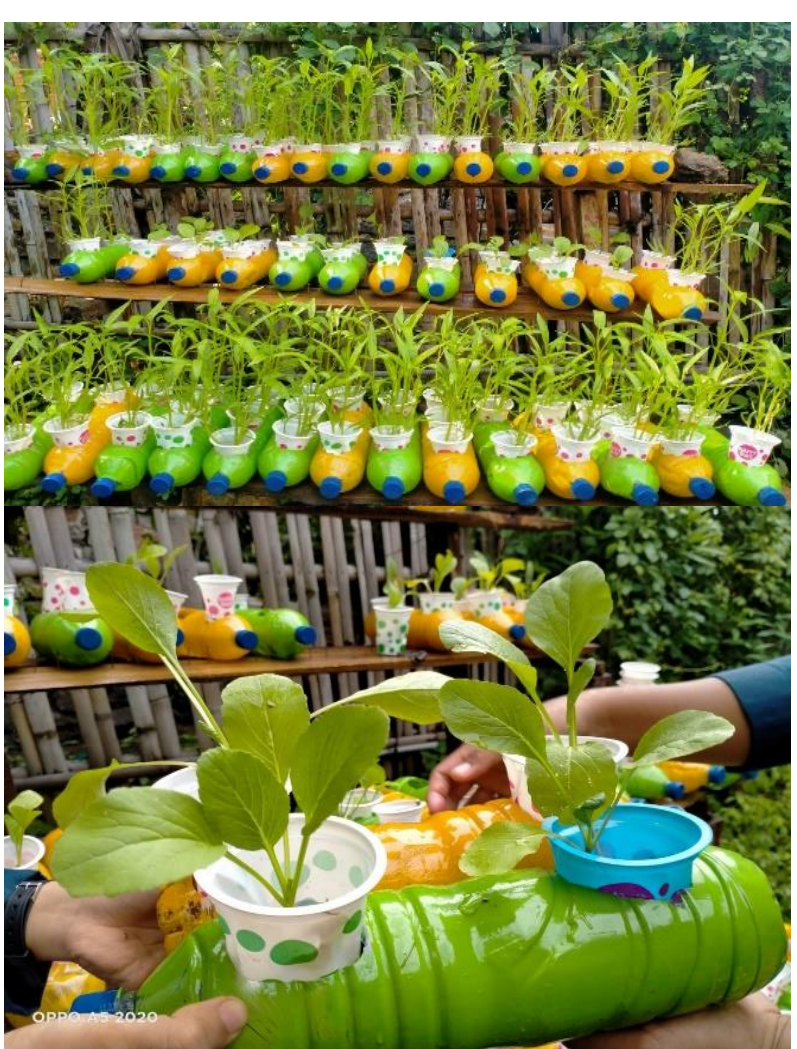

Gambar 5. Tanaman sayuran hidroponik sistem wick.

\section{Evaluasi kegiatan}

Hasil evaluasi kegiatan menunjukkan bahwa semua peserta yang mengikuti sosialisasi dan pelatihan menunjukkan keaktifan dalam mengikuti kegiatan tersebut. Masyarakat turut aktif bertanya dan menanggapi materi yang disampaikan oleh pelaksana. Sebanyak 65\% ibu rumah tangga menanam sayuran dengan hidroponik sistem wick di lahan pekarangan rumah masing-masing.

Hasil pelatihan yang terlihat jelas adalah meningkatnya pengetahuan ibu-ibu terkait teknik penanaman sayuran hidroponik sistem wick, sehingga terampil membuat persemaian bibit, membuat larutan nutrisi/pupuk organik cair, menanam dan memelihara tanaman.

Berdasarkan hasil evaluasi terungkap beberapa masalah yang dihadapi oleh peserta yaitu hasil dari sebagian semai tidak tumbuh dan beberapa bibit yang telah di pindahkan ke media tanam tidak tumbuh dengan baik/layu. Adapun tindakan yang dilakukan untuk mengatasi masalah yang dihadapi oleh peserta ini yaitu mendampingi para peserta untuk mengganti benih yang tidak tumbuh dengan benih lain yang memiliki kualitas bagus dan membuat naungan untuk tanaman agar tidak terpapar cahaya matahari langsung.

\section{Kesimpulan}

Berdasarkan hasil program yang dijalankan dapat disimpulkan bahwa budidaya tanaman sayuran hidroponik sistem wick telah berhasil memberdayakan ibu-ibu rumah tangga masyarakat Desa Cenggu dalam meningkatkan minat untuk memanfaatkan perkarangan sebagai lahan penanaman sayuran. Masyarakat memberikan respon yang sangat positif terhadap kegiatan yang dilakukan dan menilai kegiatan ini sangat bermanfaat.

\section{Ucapan Terima Kasih}

Penulis mengucapkan terima kasih kepada tim Lembaga Penelitian dan Pengabdian Masyarakat (LPPM) Universitas Mataram dan kepada masyarakat Desa Cenggu atas kesempatan yang diberikan kepada penulis untuk menjalankan program pengabdian masyarakat melalui agenda Kuliah Kerja Nyata (KKN ERA NEW NORMAL) tahun akademik 2020-2021.

\section{Daftar Pustaka}

Ariati, P. E. P. dan I. D. N. Raka 2019. Sosialisasi Hidroponik Sebagai Basis Peningkatan Perekonomian Masyarakat Merupakan Pendongkrak Nilai Tambah Pendapatan Keuangan. AGRIMETA 9(17): 53-57. http://e-journal.unmas.ac.id/index.php/agri meta/article/view/427/412

Eddy, S., D. Mutiara, T. Kartika, C. Masitoh, dan Wahyu. 2019. Pengenalan Teknologi Hidroponik Dengan System Wick (Sumbu) Bagi Siswa SMAN Negeri 2 Kabupaten Rejang Lebong Bengkulu. PengabdianMu: Jurnal Ilmiah Pengabdian kepada Masyarakat 2(4): 74-79. http://journal.umpalangkaraya.ac.id/index.ph p/pengabdianmu/article/view/804/889

Kamalia, S., P. Dewanti dan R. Soedrajad. 2017. Teknologi Hidroponik Sisten Sumbu pada Produksi Selada Lollo Rossa (Lactuca sativa L.) Dengan Penambahan $\mathrm{CaCl}_{2}$ Sebagai Nutrisi Hidroponik. Jurnal Agroteknologi 11(1):

96-104. 
https://jurnal.unej.ac.id/index.php/JAGT/arti cle/view/5451/4086

Narulita, N., S. Hasibuan dan R. Mawarni. 2019. Pengaruh Sistem dan Konsentrasi Nutrisi Terhadap Pertumbuhan dan Produksi Tanaman Pakcoy (Brassica rapa L.) Secara Hidroponik. Bernas Agricultural Research Journal 15(3): 99-108. http://jurnal.una.ac.id/index.php/jb/article/vi ew/1307/1114

Puspasari, I., Y. Triwidyastuti dan Harianto. 2018. Otomasi Sistem Hidroponik Wick Terintegrasi pada Pembibitan Tomat Ceri. JNTETI 7(1): 97-104. http://ejnteti.jteti.ugm.ac.id/index.php/JNTE TI/article/view/406/329

Ruswaji dan L. Chodariyanti. 2019. Pemberdayaan Masyarakat Desa Kepada Kelompok Ibu-Ibu PKK dan Karang Taruna Melalui Program Pelatihan "Hidroponik". Abdimas Berjaya: Jurnal Pengabdian Masyarakat 2 (1): 1-9.
https://pemas.unisla.ac.id/index.php/JAB/art icle/view/32/29

Satya, M. T., A. Tejaningrum dan Hanifah. 2017. Manajemen Usaha Budidaya Hidroponik. Jurnal Dharma Bhakti Ekuitas 1(2): 53-57. https://docplayer.info/60579382-

Manajemen-usaha-budidayahidroponik.html

Solikhah, B., T. Suryarini, dan A. Wahyudin. 2018. Pemberdayaan Ibu Rumah Tangga Melalui Pelatihan "Hidroponik". ABDIMAS 22 (2): 121-127. https://docplayer.info/136621858Pemberdayaan-ibu-rumah-tangga-melaluipelatihan-hidroponik.html

Surahman, A. M,. 2018. Penerapan Teknologi Tepat Guna (Penanam Hidroponik Menggunkan Media Tanam) Bagi Masyarakat Sosrowijawan Yogyakarta. Jurnal Pemberdayaan, Publikasi Hasil Pengabdian kepada Masyarakat 2(3): 425-430. http://journal2.uad.ac.id/index.php/jpmuad/a rticle/view/418/pdf 